\title{
Comunicación en valores y educación ambiental
}

\author{
Communication based in values and environmental education
}

\author{
María Belén BARROSO \\ Universidad de Málaga (España) \\ mbelenbarroso@gmail.com
}

Recibido: 30 de marzo 2015

Aceptado y Publicado: 30 de mayo de 2015

\section{Resumen}

La Educación Ambiental se propone como una estrategia significativa para dotar a las personas de las competencias necesarias para actuar de manera sostenible en un contexto socio-ambiental complejo y en peligroso deterioro. Para ello, enfocándose en la necesidad de recuperar el papel central de las emociones para el afianzamiento de ciertos valores, actitudes y comportamientos responsables; las organizaciones del tercer sector dedicadas a la educación ambiental, procuran desarrollar intervenciones eficaces e innovadoras a través de los medios de comunicación desde un enfoque educativo y participativo. La presente investigación surge con el objetivo de conocer los valores que la cooperativa Aula del Mar (Málaga) comunica o proyecta desde los medios gráficos de comunicación de España. En este sentido, se determinaron categorías de análisis textual para 140 noticias publicadas (2012-2015) a partir de los principios expuestos en la Carta de la Tierra (ONU, 2000). Los resultados permiten resaltar el perfil educativo en valores pro-ambientales del Aula del Mar tales como: conservación, cooperación, educación, divulgación, recuperación, responsabilidad, concienciación, investigación, prevención, solidaridad, sostenibilidad y participación; al tiempo que han permitido contribuir a generar conocimiento en torno a la vinculación entre la educación ambiental y los enfoques de comunicación en valores. 


\begin{abstract}
Environmental education is proposed as a significant strategy to equip people with the necessary skills to act sustainably in a complex socio-environmental context and suffering a dangerous deterioration. To do this, focusing on the need to restore the central role of emotions for the consolidation of certain values, attitudes and responsible behavior; third sector organizations dedicated to environmental education, seek to develop effective and innovative interventions through the media from an educational and participatory approach. This research began in order to know the values that the Aula del Mar (Málaga) communicates through the graphic media in Spain. In this sense, categories of textual analysis of 140 published reports (2012-2015) from the principles outlined in the Earth Charter (ONU, 2000) were determined. The results allow to highlight the educational profile in pro-environmental values of the Aula del Mar such as conservation, cooperation, education, outreach, recovery, responsibility, awareness, research, prevention, solidarity, sustainability and participation; while they allowed to help generate knowledge about the link between environmental education and communication approaches in values.
\end{abstract}

Palabras Clave: Comunicación, valores, educación ambiental, medios de comunicación.

Key Words: Communication, values, environmental education, media.

\title{
1. Introducción
}

\subsection{La educación ambiental}

Desde el inicio de la existencia humana, y por nuestra capacidad de razonar (superadora frente al resto de las especies que habitan el planeta), aprendimos a utilizar los recursos ofrecidos por la naturaleza para satisfacer las necesidades imperantes de cada época. Primero sólo nos interesaba sobrevivir, pero con los avances propios de una civilización adentrada en la Revolución Industrial, el tiempo adquirió un fuerte valor económico y nos vimos "obligados" a acelerar el ritmo para cubrir la demanda de una sociedad cada vez más consumista. 
Consecuentemente, aunque desarrollamos amplias capacidades tecnológicas que incrementaron los procesos y volúmenes productivos, estamos sobreexplotando los recursos no renovables en detrimento del uso de fuentes energéticas resultantes de procesos biológicos naturales; aumentando además los residuos no metabolizables. A su vez, con la modernidad la población creció exponencialmente y los procesos migratorios del campo a la ciudad se multiplicaron sin la debida planificación urbanística, social y ambiental. Todo ello ha contribuido al distanciamiento entre las personas y la naturaleza, generando problemas ambientales que deterioran su calidad de vida (Bird, 2007).

Sin embargo, los análisis de la complejidad (Morín, 1994) postulan que los cambios y la transformaciones, desde los orígenes, son los que han permitido la evolución o extinción de numerosos fenómenos tanto naturales como sociales que llevaron a presentar la realidad tal como la vemos hoy (Bonil et al, 2010). En efecto, la tensión en la relación persona-medio ambiente ha planteado una necesaria revalorización de nuestro papel como una especie más de las que integran un planeta que tiene su propio ritmo, donde sólo una parte de sus recursos son renovables y el resto merece nuestro respeto, porque "los estamos tomando prestado de nuestras generaciones futuras".

En este sentido, la ciencia ha realizado marcados esfuerzos en estudiar y comprender la esta realidad, intentando estabilizar las variables para interpretarlas. Pero el dinamismo propio del estado natural de crisis, sumado a los avances de una sociedad industrial orientada al consumo, nos ha conducido a un estado actual de "modernidad líquida" (Bauman, 2007). En este contexto la ciencia y la sociedad necesitan adaptarse a la incerteza de los acontecimientos, a la imposibilidad de alcanzar todas las respuestas. Se vuelve entonces indispensable, entender la crisis como oportunidad y la educación como tal, cobra un protagonismo a través del cual los ciudadanos pueden obtener herramientas para transformar la realidad desde una visión sustentable.

Y es en 2002, durante la Cumbre de Johannesburgo que la Educación Ambiental para el Desarrollo Sostenible (EDS) irrumpe en pos de la concienciación ética y ambiental, la formación en el afianzamiento de ciertos valores y actitudes, destrezas y comportamientos coherentes con la idea de sostenibilidad y eficaces para lograr la participación pública en el proceso de toma de decisiones y para poder actuar, individual y colectivamente, en la resolución de los problemas ambientales (Congreso Internacional de E.A., 1987).

Resulta necesario comprender entonces que el medio ambiente no se agota en la idea de entorno natural, sino que conlleva una serie de meta conceptos que permiten decodificar la complejidad del término. Estamos hablando de nociones implícitas e interdisciplinares como "sistema", "interacción", "unidad", "diversidad" y "cambio", las cuales explican que el hombre es parte de un sistema abierto y dinámico de factores 
naturales, sociales y culturales que se relacionan entre sí y determinan su vida, a la vez que son condicionados por él (Villaverde, 1985).

En efecto, la educación ambiental tiene la oportunidad de aprender de la crisis, de aprovechar el cambio para sensibilizar, divulgar y apuntar al reencuentro de sus alumnos con su medio natural y social más próximo desde la creatividad y la sensibilidad (Ausubel, 1963). El esfuerzo se multiplica en pos de formar ciudadanos competentes para tomar las decisiones correctas para actuar desde su entorno local comprendiendo sus repercusiones a nivel global.

En este marco, en el que además la problemática medio ambiental cobra mayor protagonismo en la agenda de los medios de comunicación; las organizaciones del tercer sector dedicadas a la educación ambiental, procuran llevar adelante intervenciones eficaces e innovadoras para la participación a través de por ejemplo, la implementación de acciones de comunicación y relaciones con los medios.

Al margen (o contrariamente, quizás) de la riqueza, el crecimiento material y económico que ha marcado el afán de vida de personas y países durante tantas décadas; en 2012, el concierto de países del mundo reunidos en la Asamblea General de Naciones Unidas declararon que "la felicidad y el bienestar son objetivos y aspiraciones universales en la vida de los seres humanos de todo el mundo". Sin duda, el propósito de esta nueva ecuación fue despojar a los seres humanos de la calidad de "un recurso más" que media para alcanzar el bienestar económico y material, el cual se ha vuelto desde hace ya demasiado tiempo un fin en sí mismo. Y más allá de su claro afán declarativo y (re)fundante en las políticas de los estados, se espera que traiga también consecuencias en las organizaciones de todos los sectores.

Son entonces cada vez más numerosas las evidencias científicas, que a su vez abonan las intuitivas ya existentes, que se preguntan si es la abundancia material la que traiga a priori el bienestar de las personas (Kasser y Sheldon, 2009). Y es que aunque egoísmo y solidaridad (como mecanismos de supervivencia personal y social respectivamente) no acaban de encontrar el justo equilibrio, cada vez resulta más evidente que el progreso humano (Ridley, 2011) se sustenta en el intercambio basado en el principio de confianza mutua, interdependencia, cooperación y comunicación de valores.

\subsection{Valores pro-ambientales}

Caduto (1985) definirá la articulación entre los conceptos de creencia, actitud y valor partiendo de los aportes de diversos autores (Dispoto, 1977; Rokeach, 1976 y Kolb, 1961). Una creencia es una proposición simple que puede ser consciente o inconsciente, inferida de lo que una persona dice o hace, capaz de ser precedida por la frase "Yo creo que". Cada creencia se compone de una parte cognitiva (conocimiento), una afectiva (emociones), y otra conativa (acción). Las creencias son verdaderas o falsas, pero no

Facultad de Ciencias Políticas, Sociales y de la Comunicación

Universidad de La Laguna

Avenida César Manrique, s/n; Campus de Guajara

38071 La Laguna, Tenerife (Islas Canarias - España) 
conducen necesariamente a un comportamiento determinado. Podemos describir tres tipos principales de creencias: descriptiva o existencial (creo que el sol sale por el este), evaluativa (creo que un árbol es hermoso), y prescriptiva o exhortativa (creo que los árboles deben preservarse siempre que sea posible). Las creencias se forman temprano en la vida de un niño.

El total de las creencias de una persona acerca de la realidad física y social se denomina sistema de creencias. Una agregación menor de creencias afines constituye una actitud, que "corresponde al conjunto relativamente duradero de creencias relativas a un objeto o situación que predispone para responder de manera determinada" (Kolb, 1961:70, citado por Caduto, 1985). Las actitudes condicionan gustos o disgustos por otras personas y/o situaciones.

La diferencia importante entre una creencia y una actitud es que las actitudes se encuentran siempre acompañadas por el elemento emocional e implica una tendencia hacia el comportamiento. Los valores están a su vez formados por una fusión de actitudes estrechamente alineadas. Un valor es una convicción perdurable de un modo específico de conducta o estado final de existencia socialmente preferible frente un modo opuesto de comportamiento (Dispoto, 1977). Por su parte, Hosley (1977) dirá que un sistema de valores es una jerarquía de ideales o valores, dispuestos en orden de importancia.

Es aquí donde debemos trabajar para generar cambios fundamentales en nuestras formas de vida. A partir de 1997, la comisión para la Carta de la Tierra se conformó para aunar esfuerzos que nos permitan darnos cuenta que, una vez satisfechas las necesidades básicas, el desarrollo humano se refiere primordialmente a ser más, no a tener más. Y para ello necesitamos (re)pensar una visión compartida sobre los principios y valores básicos que brindan un fundamento ético para la comunidad mundial.

A partir de estos principios y valores se ha elaborado un conjunto de lo que denominamos valores pro-ambientales (Ver cuadro № 1) que deberían ser la base del accionar individual y colectivo en pos del desarrollo sostenible basado en el respeto hacia la naturaleza, los derechos humanos universales, la justicia económica y una cultura de paz (Carta de la Tierra, 2000).

El desarrollo de este sistema de valores se encuentra determinado por un proceso de socialización, la cultura en la que nos encontramos inmersos determinará nuestro modo de vida. En este sentido, la sociedad puede verse como una colección de influencias que interactúan estrechamente valor para moldear el sistema de valores de cada persona desde su nacimiento. Algunos de los actores que comúnmente infieren sobre los valores en la sociedad según Caduto (1985) son: los padres y el entorno familiar; los maestros, administradores y escuelas; las autoridades religiosas; compañeros; el gobierno; el ambiente de trabajo; los medios de comunicación; la literatura y las leyes.

Facultad de Ciencias Políticas, Sociales y de la Comunicación

Universidad de La Laguna

Avenida César Manrique, s/n; Campus de Guajara

38071 La Laguna, Tenerife (Islas Canarias - España) 
Cuadro 1: Valores pro-ambientales inscriptos en los principios de la Carta de la Tierra ${ }^{1}$

\begin{tabular}{|c|c|c|}
\hline \multicolumn{2}{|r|}{ Principios y Valores de la Carta de la Tierra } & $\begin{array}{c}\text { Valores } \\
\text { Pro-ambientales }\end{array}$ \\
\hline \multirow{4}{*}{$\begin{array}{l}\text { I. Respeto y } \\
\text { cuidado de } \\
\text { la vida. }\end{array}$} & 1. Respetar la Tierra y la vida en toda su diversidad. & Respeto \\
\hline & $\begin{array}{l}\text { 2. Cuidar la comunidad de la vida con entendimiento, compasión y } \\
\text { amor. }\end{array}$ & Amor \\
\hline & $\begin{array}{l}\text { 3. Construir sociedades democráticas que sean justas, participativas, } \\
\text { sostenibles y pacíficas. }\end{array}$ & Participación \\
\hline & $\begin{array}{l}\text { 4. Asegurar que los frutos y la belleza de la Tierra se preserven para } \\
\text { las generaciones presentes y futuras. }\end{array}$ & Sostenibilidad \\
\hline \multirow{4}{*}{$\begin{array}{l}\text { II. Integridad } \\
\text { ecológica }\end{array}$} & $\begin{array}{l}\text { 5. Proteger y restaurar la integridad de los sistemas ecológicos de la } \\
\text { Tierra, con especial preocupación por la diversidad biológica y los } \\
\text { procesos naturales que sustentan la vida. }\end{array}$ & $\begin{array}{l}\text { Conservación/ } \\
\text { Recuperación }\end{array}$ \\
\hline & $\begin{array}{l}\text { 6. Evitar dañar con el mejor método de protección ambiental y, cuando } \\
\text { el conocimiento sea limitado, proceder con precaución. }\end{array}$ & Prevención \\
\hline & $\begin{array}{l}\text { 7. Adoptar patrones de producción, consumo y reproducción que } \\
\text { salvaguarden las capacidades regenerativas de la Tierra, los derechos } \\
\text { humanos y el bienestar comunitario. }\end{array}$ & $\begin{array}{l}\text { Responsabilidad/Bie } \\
\text { n común }\end{array}$ \\
\hline & $\begin{array}{l}\text { 8. Impulsar el estudio de la sostenibilidad ecológica y promover el } \\
\text { intercambio abierto y la extensa aplicación del conocimiento adquirido. }\end{array}$ & $\begin{array}{l}\text { Investigación/ } \\
\text { Divulgación }\end{array}$ \\
\hline \multirow{4}{*}{$\begin{array}{l}\text { III. Justicia } \\
\text { social y } \\
\text { económica }\end{array}$} & 9. Erradicar la pobreza como un imperativo ético, social y ambiental. & $\begin{array}{l}\text { Desarrollo humano/ } \\
\text { Solidaridad }\end{array}$ \\
\hline & $\begin{array}{l}\text { 10. Asegurar que las actividades e instituciones económicas, a todo } \\
\text { nivel, promuevan el desarrollo humano de forma equitativa y sostenible. }\end{array}$ & Equidad/Justicia \\
\hline & $\begin{array}{l}\text { 11. Afirmar la igualdad y equidad de género como prerrequisitos para } \\
\text { el desarrollo sostenible y asegurar el acceso universal a la educación, } \\
\text { el cuidado de la salud y la oportunidad económica. }\end{array}$ & Igualdad de Género \\
\hline & $\begin{array}{l}\text { 12. Defender el derecho de todos, sin discriminación, a un entorno } \\
\text { natural y social que apoye la dignidad humana, la salud física y el } \\
\text { bienestar espiritual, con especial atención a los derechos de los } \\
\text { pueblos indígenas y las minorías. }\end{array}$ & Integración \\
\hline \multirow{4}{*}{$\begin{array}{l}\text { IV. } \\
\text { Democracia, } \\
\text { no violencia y } \\
\text { paz }\end{array}$} & $\begin{array}{l}\text { 13. Fortalecer las instituciones democráticas en todos los niveles y } \\
\text { brindar transparencia y rendimiento de cuentas en la gobernabilidad, } \\
\text { participación inclusiva en la toma de decisiones y acceso a la justicia. }\end{array}$ & Cooperación \\
\hline & $\begin{array}{l}\text { 14. Integrar en la educación formal y en el aprendizaje a lo largo de la } \\
\text { vida, las habilidades, el conocimiento y los valores necesarios para un } \\
\text { modo de vida sostenible. }\end{array}$ & Educación \\
\hline & 15. Tratar a todos los seres vivientes con respeto y consideración. & $\begin{array}{l}\text { Fraternidad/ } \\
\text { Convivencia } \\
\end{array}$ \\
\hline & 16. Promover una cultura de tolerancia, no violencia y paz. & Paz/Armonía \\
\hline
\end{tabular}

${ }^{1}$ Carta de la Tierra en http://www.earthcharterinaction.org/invent/images/uploads/echarter_spanish.pdf. Consultada el 25/05/15.

Facultad de Ciencias Políticas, Sociales y de la Comunicación

Universidad de La Laguna

Avenida César Manrique, s/n; Campus de Guajara

38071 La Laguna, Tenerife (Islas Canarias - España) 


\subsection{Los medios y la imagen publicada}

Capriotti (2009) dirá que para realizar una evaluación mediática se deben analizar dos procesos de comunicación: por un lado, el que se genera entre la organización y la relación con los medios en sí, o sea cuál es el tratamiento que recibe de los periodistas; y por otro, el proceso de comunicación que se genera entre el medio masivo y los públicos, es decir, qué leen los públicos de lo que dicen los medios sobre la organización. No debemos por ello, partir de la premisa errónea de creer que los medios son un canal -indirecto- de creación de imagen, ya que la imagen publicada tiene su fundamento en los discursos plasmados en los medios de comunicación y no en las estructuras mentales de los públicos como hemos indicado anteriormente.

En efecto, el estudio del fenómeno de la imagen publicada puede ser abordado desde perspectivas diferentes en función del momento del proceso productivo de la construcción de textos periodísticos en el que nos situemos. Existen dos fases: el estudio del medio como institución y sus contextos de producción; y el estudio del análisis del mensaje en sí, es decir, el estudio de la forma definitiva adoptada por la noticia, el contenido concreto publicado. Las posibilidades de estudio en esta segunda fase pasan por el análisis de la dimensión puramente formal de la noticia (espacio destinado, ubicación concreta, etc.) y por el análisis de los contenidos transmitidos (temáticas, prioridades, enfoques, presencia de actores y acciones, asociaciones...). Es en esta segunda opción en la que se sitúa el modelo de Losada Díaz (2005).

Existen también estudios enfocados sobre el impacto o estudio de la recepción del mensaje por su audiencia, es decir, el estudio de los efectos de los medios. Son las consecuencias, evaluadas o supuestas de la acción de las informaciones en la mente de las audiencias.

En este línea, pero incidiendo más directamente en la construcción mental de la realidad abocada por los medios se pronuncia Vázquez Medel, que subraya que "lejos de estar (la realidad) fundamentada en nuestra experiencia directa del mundo, nuestras imágenes de la realidad social provienen de los medios de comunicación" (1999: 221). Debido a esta influencia, el autor añade:

Pero no se trata sólo de influir en el contenido de la mente, sino también en nuestras pautas de acción en el mundo. Los medios de comunicación inciden en la construcción no sólo de imágenes inmediatas del mundo (preceptos) o de ideas sobre él (conceptos), sino también en la regulación de nuestra interacción con los seres y las cosas (afectos). No sólo se trata de una incidencia informativa, puramente nocional. Se trata de la construcción de sistemas de valores, de universos axiológicos, y de pautas de acción” (Vázquez Medel, 1999: 223).

En definitiva, los medios operan en la actualidad como los agentes que proporcionan a amplias capas sociales las informaciones y valoraciones que conforman las opiniones

Facultad de Ciencias Políticas, Sociales y de la Comunicación

Universidad de La Laguna

Avenida César Manrique, s/n; Campus de Guajara

38071 La Laguna, Tenerife (Islas Canarias - España) 
sobre las cuales rigen después sus comportamientos y toman sus decisiones. Pero hay que hacer una aclaración, ya que esto no significa, en ningún caso, que podamos hacer el trasvase de los términos de Imagen y de Imagen Publicada de forma gratuita, de manera que puedan considerarse como realidades sinónimas.

Por ello, el estudio y medición de la Imagen Publicada no está completo en tanto y en cuento resulta imposible la evaluación completa de la imagen que los medios generan a través de la publicación de los textos si no son escuchados los propios destinatarios de la información, los lectores (como se ha indicado antes, conforme al esquema por el cual cada receptor recibe, asimila e interpreta la información en función de su propio contexto y situación personal). A partir de la premisa de que los lectores son los responsables principales de la imagen final que deciden utilizar en el futuro y de que, paralelamente, los medios tienen capacidad para influir en estos lectores en la asignación de los atributos que acaban perfilando esta imagen, esta propuesta quedará en la línea de evaluar objetivamente el material publicado por los medios -al margen de su probable influencia en uno u otro sentido- a partir de una triple perspectiva que da origen a la metodología aplicable posteriormente. Esta triple dimensión se basa en:

- La información que se pone a disposición de los receptores (y, por lo tanto, la que se excluye).

- El modo de presentación de ciertos temas y la relevancia periodística que se les otorga.

- La valoración de las acciones llegadas a cabo por los actores presentes en los textos.

Esta propuesta utiliza los desarrollos propios de la técnica de análisis de contenido, a partir de las aportaciones de autores clásicos como Bardin (1996) o Krippendorff (1990), un material enriquecido en dos vertientes: en primer lugar, en la parte cualitativa del análisis (elección de variables y subvariables) y, en segundo lugar, la codificación estadística de los resultados.

Además, de esta apreciación es necesario apuntar que partimos de la premisa de que en el proceso comunicacional que se genera en los medios de comunicación están implícitos dos componentes fundamentales que influyen en la alimentación de los imaginarios sociales, como son las objetividad y la parcialidad. La objetividad, entendida como referencia a hechos susceptibles de ser confirmados y contrastados a través de diferentes tipos de fuentes; y por otro la parcialidad, entendida como la toma de posición de cada medio frente a esos mismos hechos. En ese sentido, sostenemos que las producciones periodísticas son parciales (reflejan tomas de partido a favor o en contra de determinados intereses de clase o grupos) y tienen como objetivo final la creación de sentidos comunes hegemónicos.

Ello también nos lleva a discernir en las aportaciones vinculadas a las unidades informativas como son la textual, limitada a la unidad de actuación lingüística, y el

Facultad de Ciencias Políticas, Sociales y de la Comunicación

Universidad de La Laguna

Avenida César Manrique, s/n; Campus de Guajara

38071 La Laguna, Tenerife (Islas Canarias - España) 
contexto -unidad extratextual de interpretación sociocultural que forma parte de los niveles cognitivos de quien recibe la información- como subraya Losada Díaz (2002), siendo esta última dimensión la que afecta y confiere a los textos una incidencia diferente en cada receptor y de forma extensiva se prolonga al grupo de individuos que configuran un mismo público atendido por la organización. En este caso que planteamos, esos públicos no reciben la información de forma directa, sino mediatiza por el medio de comunicación, siendo un portavoz que escapa al control de la propia organización.

Estos valores inciden de forma directa en otro ingrediente que es la credibilidad, el gran basamento de los medios de comunicación y que, según mantiene Losada Díaz (2002: 29), contribuye al fortalecimiento de la imagen de las organizaciones en el imaginario colectivo a través de aquellas referencias que se plasman en la prensa.

La credibilidad es un punto de arranque muy valioso para la consecución de apreciaciones, opiniones y percepciones sobre una organización, al ser los medios de comunicación un soporte que no supone para el receptor externo -y hasta para el interno- ninguna relación con los intereses de la organización, ninguna voluntad propagandística que trate de ocultar la verdadera realidad.

Por lo que se incide en que los medios van a ser una plataforma de consolidación de las identidades de las organizaciones, de cara al conjunto de los públicos que se nutren de su servicio y que se ven afectados por sus representaciones en el universo mediático y en su repercusión colectiva.

\section{Caso de estudio, objetivo y metodología.}

El Aula del Mar es una cooperativa que trabaja desde 1989 por la educación y participación en la conservación de los recursos naturales y en la mejora de la calidad ambiental y de vida, desde la sostenibilidad y la solidaridad. Sus actividades cubren aspectos tan diversos como la gestión del Museo Alborania dedicado al estudio y protección del Mar de Alborán, educación ambiental para la comunidad educativa y público en general, acuicultura, asesoramiento ambiental, investigación y publicaciones científicas. En la actualidad es un centro implicado en diferentes ámbitos, entre ellos la comunidad educativa, sector pesquero y acuícola, entidades conservacionistas, culturales y científicas, administraciones públicas y medios de comunicación.

Por medio de esta investigación se pretende conocer los valores pro-ambientales que el Aula del Mar comunica o proyecta a través de los medios de comunicación. El diseño metodológico llevado a cabo para realizar este estudio se ha basado en una investigación de tipo interpretativa que permitió caracterizar la imagen publicada del Aula del Mar analizando el contenido de un total de 140 notas de prensa que tienen como 
protagonista a la organización durante el periodo febrero 2012- mayo 2015. Una primera etapa de este proyecto se llevó adelante con las exposiciones del Aula del Mar en los medios en el año 2014, resultados que fueron discutidos en el marco del First International Conference for Positive Communication "Happiness \& Communication: lights and shadows" celebrado en Sevilla, España en marzo de 2015 (Barroso, Álvarez; 2015).

La muestra de nuestro estudio está compuesta de 140 exposiciones mediáticas del Aula del Mar en medios gráficos de España, en particular de Andalucía durante el periodo febrero 2012- mayo 2015.

De acuerdo con la técnica de investigación empleada en este estudio se ha desarrollado un cuadro de análisis de contenidos en el que registraremos las noticias aparecidas sobre el caso de estudio.

Dicha herramienta se adecua a nuestras principales variables/categorías de estudio:

- Tratamiento del medio

- Fuentes informativas

- Agenda de temas vinculados

- Públicos afectados

- Ámbitos de interés

- Valores e imagen asociada.

\section{Resultados}

Los resultados son presentados en función de las variables que han determinado el análisis. Con esta estructura podremos realizar un análisis de cada nota y una posterior comparación para poder alcanzar unas conclusiones comunes del estudio. A continuación ofrecemos los resultados obtenidos del análisis llevado a cabo en las noticias publicadas sobre el Aula del Mar durante el periodo febrero 2012- marzo 2015.

Los medios gráficos que han publicado la mayor cantidad noticias sobre el Aula del Mar en el periodo analizado fueron: La Opinión de Málaga (35), Diario Sur (33) y Málaga Hoy (28). De las cuales, un $57,1 \%$ se encontraron disponibles en formato digital y un $42,9 \%$ en versión papel. Cabe destacar que el formato de las apariciones fue el de noticia en un $98,6 \%$ y el año con mayor presencia fue el 2013. En dicho periodo se publicaron el $47,7 \%$ de las notas relevadas con picos de publicaciones durante julio, correspondiente al mes con mayor número de actividades de verano desarrolladas por la organización. Sin embargo, durante el año 2014 fue posible observar mayor constancia en las exposiciones.

Respecto a la fuente informativa, el $90 \%$ de las notas publicadas procedían del propio periódico y un $10 \%$ de las agencias noticias Europa Press y EFE. En cuanto a la 
valoración de las notas analizadas, un 96,4\% tuvieron un enfoque positivo y un 3,6\% mantuvieron una mirada neutral hacia la cooperativa. Las noticias intentaron llegar en un $97,1 \%$ al público en general con alcance regional (75\%) y local (17\%).

Las temáticas abordadas en noticias publicadas sobre el Aula del Mar versan en su mayoría sobre las acciones de recuperación de especies marinas amenazadas, el financiamiento de la organización, el lanzamiento de proyectos de educación ambiental y la agenda de eventos culturales. Los medios de comunicación han promocionado distintos eventos educativos y culturales organizados por el Aula del Mar en cooperación con distintas entidades tales como: las ediciones de la Semana del Mar, acciones solidarias, Programas de Reciclaje, Jornadas del Mar, etc. En paralelo, se destacó la labor de la cooperativa a través de la publicación de firmas de convenidos y premios recibidos.

En lo que respecta a las menciones de marca, sobre un total de 234 menciones en las 140 notas analizadas, el 53\% correspondieron al Aula del Mar. No debemos dejar de destacar que dicha marca apareció en 125 notas de la muestra seleccionada. En segundo lugar, encontramos a la marca CREMA con un 18\% en 42 exposiciones, seguida del Centro de Recuperación de Especies Marinas Amenazadas con un 16\% del total en 38 noticias. Por último, el Museo Alborania tuvo apenas un 10\% de las menciones publicadas en 24 notas, además de un $2 \%$ de la porción del total apareciendo sólo como Alborania en 5 oportunidades.

En lo que concierne a los valores asociados, el Aula del Mar desde sus cuatro marcas (Aula del Mar, Centro de Recuperación de Especies Marinas Amenazadas, CREMA y Museo Alborania) se vinculó, de acuerdo a la cantidad de menciones, con valores tales como: conservación (106), cooperación (96), educación (66), divulgación (60), recuperación (52), responsabilidad (47), concienciación (45), investigación (39), prevención (22), solidaridad (18), sostenibilidad (18) y participación (7). Sin embargo, ciertos valores que si bien no fueron mencionados de manera explícita en las noticias analizadas quizás por ser más abarcativos y generales, entre ellos: amor, paz, armonía, convivencia y el respeto; podrían incluirse en la lista ya que se encuentran directamente relacionados con los valores asociados a la cooperativa en las exposiciones mediáticas tomadas como muestra.

\section{Conclusiones}

De acuerdo a las problemáticas propias del contexto socio-ambiental actual, resulta esencial poner énfasis en la importancia de estimular la práctica de valores en los procesos educativos para la construcción de interacciones saludables y constructivas entre las personas y el medio ambiente (Barraza, 1998). En este marco, cobran

Facultad de Ciencias Políticas, Sociales y de la Comunicación

Universidad de La Laguna

Avenida César Manrique, s/n; Campus de Guajara

38071 La Laguna, Tenerife (Islas Canarias - España) 
relevancia los medios de comunicación y los mensajes generados a partir de los distintos actores sociales, los mismos pueden ser utilizados como herramienta de persuasión sobre las creencias que orientarán valores y determinarán comportamientos responsables.

En esta línea, por medio del presente estudió fue posible determinar que la cooperativa Aula del Mar promueve a través de sus actividades una serie valores pro-ambientales, presentes también en la Carta de la Tierra (ONU, 2000), que se reflejaron en las 140 exposiciones mediáticas tomadas como muestra: conservación, educación, divulgación, recuperación, responsabilidad, concienciación, investigación, prevención, solidaridad, sostenibilidad y participación. Por otro lado, aparecen en forma implícita tanto en las noticias publicadas, en la representación de los periodistas, como en el perfil organizacional valores más amplios como: respeto, amor, armonía, convivencia y paz.

Estos valores se impulsan a través del desarrollo y publicación de acciones tales como: la recuperación de especies marinas amenazadas y especialmente el caso de la reintroducción de tortugas y delfines al mar; el diseño y ejecución de diversas campañas de educación y concienciación sobre el respeto y conservación del patrimonio natural y cultural; los eventos de divulgación de científica y el desarrollo de acciones solidarias, entre otras.

En síntesis, el Aula del Mar presenta un enorme potencial comunicativo y educativo, con la posibilidad de explotar la riqueza de sus programas y formar en valores que apunten al imperante cambio social hacia la sostenibilidad y el bienestar.

\section{Bibliografía}

Ausubel, D.P. (1963). The psychology of meaningful verbal learning. New York: Grune and Stratton.

Barraza, L. (1998). Conservación y medio ambiente para niños menores de 5 años. Especies, Revista sobre conservación y biodiversidad, 7, 19-23.

Barroso, M. B. y Álvarez Nobell, A. (2015): Comunicación positiva en educación ambiental: la construcción de una imagen mediática basada en valores pro ambientales. El caso AULA DEL MAR de Málaga, en el First International Conference for Positive Communication "Happiness \& Communication: lights and shadows". Universidad Loyola Andalucía. Sevilla, España. ISBN: 222-84-15698-06-7.

Bauman, Z. (2007). Los retos de la educación en la modernidad líquida. Gedisa.

Bird, W. (2007). Natural thinking: Investigating the links between the natural environment, biodiversity and mental health. Reading: Royal Society for the Protection of Birds.

Bonil, J., Junyent, M. \& Pujol R. (2010). Educación para la Sostenibilidad desde la perspectiva de la complejidad. Revista Eureka sobre Enseñanza y Divulgación de las Ciencias, № ${ }^{\circ}$ 
Caduto, Michael J. (1985). "Guide on environmental values education." Environmental Education Series. No. 13. UNESCO.

Capriotti, P. (2009). Branding Corporativo. Fundamentos para la gestión estratégica de la Identidad Corporativa. Claves del valor intangible de las empresas. Madrid: Pirámide.

Congreso Internacional de Educación y Formación sobre Medio Ambiente, Moscú (1987): http://aulaverde.ujaen.es/files averde/Libro\%20Blanco\%20Educacion\%20Amb iental\%20Espa\%C3\%B1a.pdf, (recuperada el 25 de mayo de 2015).

Kasser, T. y Sheldon, K. M. (2009). Time affluence as a path toward personal happiness and ethical business practice: empirical evidence from four studies. Journal of Business Ethics, 84, p. 243-255.

Krippendorff, K. (1990). Metodología de análisis de contenido. Teoría y Práctica. Barcelona: Ediciones Paidós Ibérica.

Losada Días, J. (2005). "Acercamiento al estudio de la Imagen Publicada: definición y casos", en Castillo Esparcia, A. Comunicación Organizacional, Málaga: Clave Aynadamar.

Morin, E., y Pakman, M. (1994). Introducción al Pensamiento Complejo .Barcelona: Gedisa.

Organización de las Naciones Unidas (2000). Carta de la Tierra. Disponible en http://www.earthcharterinaction.org/invent/images/uploads/echart er spanish.pdf (recuperada el 25 de mayo de 2015).

Ridley, M. (2011). El optimista racional. Madrid: Taurus.

Vázquez Medel, M. A. (1999). "Los medios de comunicación y la construcción social de la realidad" en Chaparro, M. (Ed.): La democratización de los medios. II Congreso de radios y televisiones locales, públicas y alternativas, Sevilla: Diputación de Sevilla, 207-226.

Villaverde, M. N. (2009). La educación ambiental, una genuina educación para el desarrollo sostenible. Revista de Educación, (1), 195-217.

\section{Forma de citar este artículo en bibliografías}

BARROSO, M. B. (2015): "Comunicación en valores y educación ambiental", en Revista PANGEA № 6, Volumen № 1, páginas 36 a 48. Tenerife: Red Académica Iberoamericana de Comunicación. Recuperado el de de 2 de: http://www.revistapangea.org 